\title{
Mapping of Physical Vulnerability in Tiger Habitat Areas: A Case Study of Tiger Corridor of Rajasthan, India
}

\author{
Bhanwar Vishvendra Raj Singh ${ }^{\mathrm{a},}$, Anjan Sen ${ }^{\mathrm{b}}$ \\ ${ }^{a}$ Department of Geography, Faculty of Earth Sciences, Mohanlal Sukhadia University, Udaipur, India, 313001, \\ bhanwarsa28@gmail.com \\ ${ }^{b}$ Department of Geography, Delhi School of Economics, University of Delhi, Delhi, 110007, dr.anjansen@gmail.com \\ * Bhanwar Vishvendra Raj Singh, bhanwarsa28@gmail.com
}

\begin{abstract}
Nowadays, biodiversity is very rapidly diminishing from all over the globe due to unsustainable practices of natural resource by anthropogenic activities. It is an unhealthy for ecosystem services. In the biodiversity, tiger is an icon of healthy wildlife, which is known as a vital factor for maintaining universal food chain system. The research paper is focused on "Mapping of Physical Vulnerability of Tiger Habitat Areas: A Case Study of Tiger corridor of Rajasthan, India" it's a micro level Study based on primary and secondary data through GIS mapping, habitat ranking and Q-Q plot. All five physical factors to inter-connect and overlay of the ranking of tiger habitats for the physical vulnerability. Especially, core and periphery of vulnerability have obtained from the Multispectral images from ETM and ETM+ sensors of Landsat and LISS-III and AWiFS sensors of Resourcesat-satellites. The study examines the spatial pattern physical vulnerability and suitability of tiger corridor of Rajasthan. Tiger Landscape change within all ecological zones has been evaluated. The Landsat TM and ETM imagery has been used to produce LULC classification maps for both areas utilising a hybrid supervised/unsupervised methods. LULC changes are measured using landscape metrics and change maps created by post-classification through change detection. Using all the raster maps and the final change detection of the reserve has been done through spatial analysis using the raster calculator tool in ArcGIS, Erdas, Statistical tool and MS Excel 13. The study comes out with physical vulnerability in core and periphery areas of the tiger corridor. The research addressed vulnerability of tiger habitat, human encroachment, impact on tiger habitat, intervene of domestic animals, and the migration in core and periphery areas, finally, the situation of physical vulnerability would be alarming for biodiversity of tiger corridor, specially buffer areas.
\end{abstract}

Keywords: Tiger corridor, Tiger habitat vulnerability, Human encroachment, Tiger conservation

\section{Introduction}

In the $21^{\text {st }}$ century, we are using unsustainable environmental resources across the globe. Since human intervention has rapidly increased in the biodiversity and ecosystem, which has resulted in the most adverse impact on environmental properties. Consequently, phenomena such as climate change, environmental degradation, overpopulation, genetic engineering, pollution, and resources depletion is happening around the world. It is are bringing up lot of modification of vegetation, biodiversity, air, water, soil, and land productivity (Xiubin, 1996).

Meanwhile, the relationship between man environments developed in the early stages of life. Human lives in the kingdom of nature and interacts with it constantly. The influence of nature is visible in the form of air we breathe, water we drink, the food we eat, and the flow of energy and information. 
Many changes in the environment not only results in harmful but it can alarm to the human race. In terms of the climate change, starting in 2000, the $\mathrm{CO}_{2}$ emissions into the atmosphere reached levels that were in excess of the worst-case scenarios produced by the IPCC (Raupach et al. 2007). The same is true for the melting of arctic ice (Stroeve et al. 2007).

The climate change could surpass habitat destruction as the greatest global threat to biodiversity over the next several decades (Leadley et al. 2010). Meanwhile, biodiversity is related to the wealth of species and ecosystems. It is of great importance at global and local levels. But nowadays we are gradually moving towards mass consumption of biodiversity. Therefore, there is harmful for man environment relationship.

There are occurring unhealthy phenomena with nature such as habitat loss, habitat fragmentation, corridor restrictions, aquatic habitat damage, interruption of the biogeochemical cycle and indirect impacts such as accessibility, ecological disequilibrium, contamination of the biota, fires, transmission of disease etc.

According to IPCC 2007 and 2014, a vulnerability is a susceptibility to the adverse effects of climate change and other stressors. In this definition, vulnerability is composed of three distinct but related components, exposure, sensitivity and adaptive capacity. Introduction is the character, magnitude and rate of change a species experiences and includes both direct and indirect impacts of climate change.
For illustration, exposure may take the form of deviations in temperature, precipitation, and extreme events, but could also comprise habitat shifts due to changing vegetation or ocean acidification. Sensitivity to climate change provides a sign of the degree to which a species or habitat is likely to be affected or alert to climate change, and is linked to its dependence on current environmental and ecological conditions. Sensitivity factors could include temperature requirements or dependence on a particular hydrological regime. Lastly, adaptive capacity is the ability of a species to cope and persist under changing conditions done local or regional Acclimatisation, dispersal or migration, adaptation, and/or evolution (Dawson et al. 2011; Glick et al. 2011).

India is richly endowed with biodiversity harbouring an estimated 10 percent of the plant species and 7 percent of the animal species found in the world, which is remarkable given that the country represents only 2 percent of the world's land mass (Kothari, 1997). India is considered sixth among the 12 megadiversity regions of the world and also has two of the world's biodiversity hotspots recognised by the international conservation community.

In the biodiversity, a tiger is the icon of good health and good fortune of the ecosystem. By conserving and saving tigers, the entire wilderness of ecosystem is conserved. Tigers constitute the top carnivores in the ecosystem services and sit on zenith of the food chain. The remove of a top carnivore from an ecosystem can have an impact on the relative abundance of herbivore species within a guild. 
Nowadays, we are making millions of dollar efforts for tiger conservation because of this species is contributing several advantages in ecosystem services. "As saving tigers is our test, if we pass, we get to keep the planet", while tiger lands support tigers, their prey, and a vast amount of biodiversity, in local and global scale.

\section{The Study Area}

Tiger corridor of Rajasthan is located between latitudes $25^{0} 52^{\prime} 071^{\prime \prime} \mathrm{N}$ to $26^{0} 33^{\prime} 713^{\prime \prime} \mathrm{N}$ to Longitudes $75085^{\prime} 84.0^{\prime \prime} \mathrm{E}$ to $77^{\circ} 02^{\prime} 48.0^{\prime \prime} \mathrm{E}$ at the junction (Great boundary fault) of Aravalis and Vindhyan ranges. It is Core area 1113.36 sq.km. And Buffer area is a 297.92 sq.km. It is a total geographical area of 1411.28 sq. Km. The Tiger corridor of Rajasthan is connecting from Keoladeo, Van Vihar, Ranthambhore, Sawai Mansingh,Ramgarh, Jawahar Sagar and Dara sanctuaries falling under Bharatpur, Karauli, Sawai Madhopur, Kota, Bundi, Chittorgarh and Jhalawar districts.

It is the single most massive expanse, of dry deciduous Anogeissus pendula forest left intact in India. In the present time, only Ranthambore tiger reserve have 60 plus tigers and few tiger in others tiger habitat also. Ranthambore the most hotspot tiger reserve and marks the transition zone between the real deserts and seasonally wet peninsular India.

Recently, this site will be restored through India and Japan Government and developed with the help of a Rs.1,153 crore grant from the Japan International Cooperation Agency (JICA) for implementing the Rajasthan Forestry and Biodiversity Project (RFBP) in select areas of the state, over a period of eight years between 2011 to 2019. (Figure 1, Source: NATMO, NTCA, 2015)

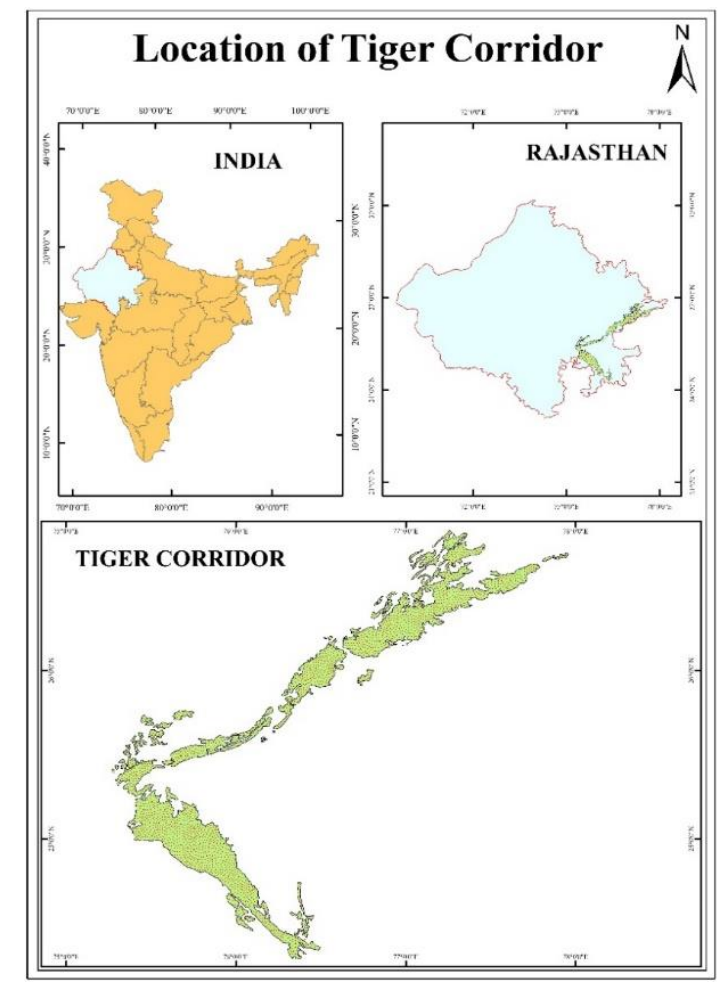

Figure 1. Tiger Corridor of Rajasthan, India

\section{Research Methodology}

The data has been collected from both primary and secondary sources, primary data has been collected from questioners, observation, field work, personal interviews and others qualitative skills. Secondary data has collected from numerous institutions, research centres and public organisation such as the Ministry of Environment and Forest and Climate Change (MoEFCC), National Tiger Conservation Authority (NTAC) established under the Wildlife (Protection) Amendment Act 1972, National Atlas and Thematic Mapping Organization (NATMO), Indian Remote Sensing Satellites available with National Remote Sensing Agency (NRSA), Hyderabad, The Department of Forest (Government of Rajasthan), Ranthambhore Van Vibhag, Wildlife Institute of India (WII), The Convention on International Trade in Endangered Species of Wild Fauna and Flora (CITES). 


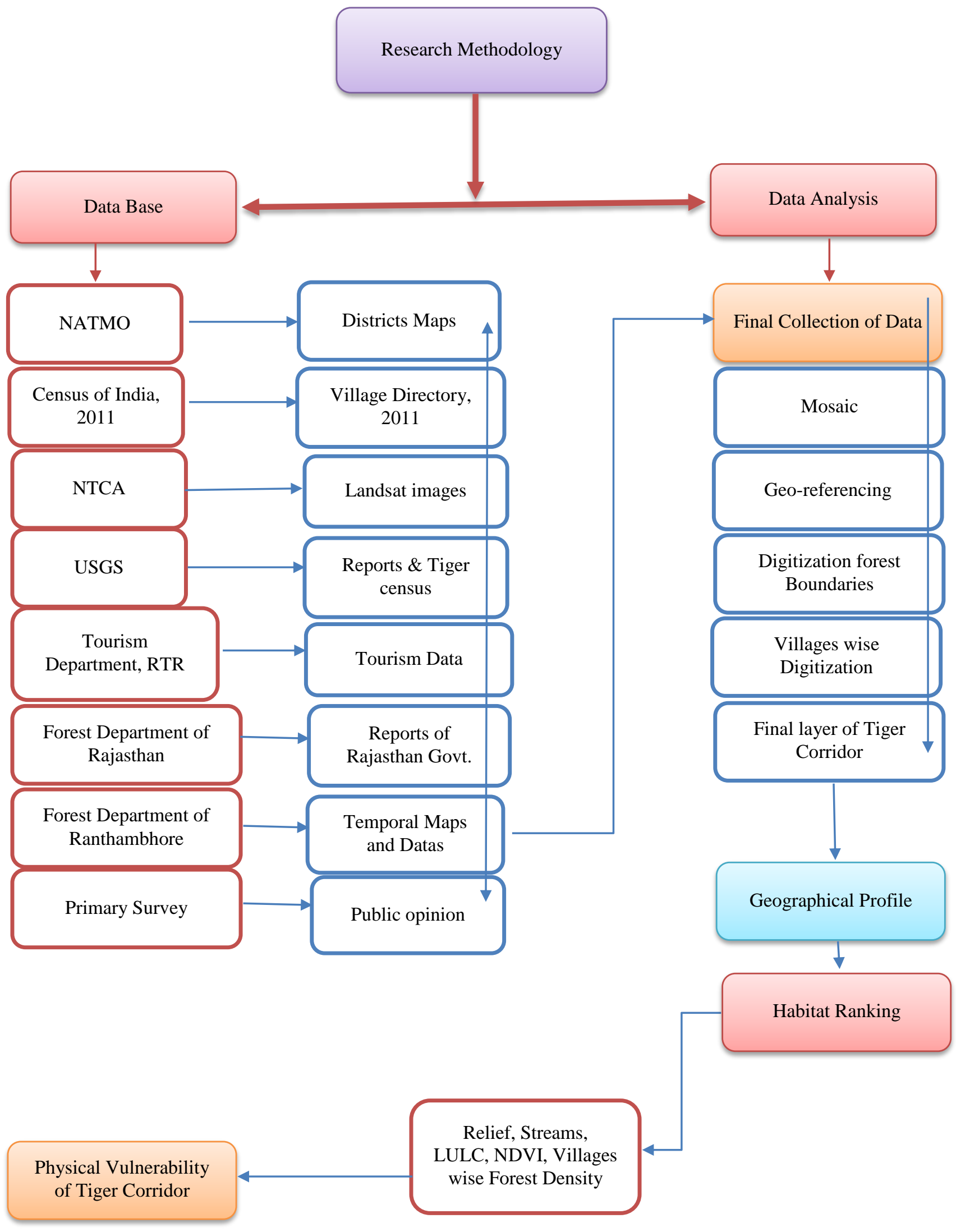

Figure 2. Data base and Research Methodology 
The secondary and primary data has been collected and scrutinized for data analysis. In this process, NATMO districts maps draw for forest reserve boundary and the mosaic to create a single plate which is a most essential part of data analysis. After digitization of the study area, create a boundary of corridor as well as village boundaries also. In the methodology, there has been taken five variable for physical indicators to assess the vulnerability of tiger corridor as a Relief, Ndvi, Streams, Lulc and Forest density of village wise factors (1499 villages).

The demographic data obtained from village directory 2011 and has been attached to the digitized map and raster maps will be created using those demographic attributes. The physical indicators are collected in raster formats. Using all the raster maps the final delineation of the corridor has been done through spatial overlay analysis using the raster calculator tool in ArcGIS and ERDAS IMAGINE. The software used for the purpose are Erdas 14 and ArcGIS 10.2 The data collected through a primary survey which was analyzed using the software like Microsoft Excel 2010 and SPSS 15.0. Linkert scale has been also be used to quantify the perception of respondents.

\section{Result and Discussion}

The physical vulnerability of tiger corridor area is dependent on its geographic proximity and landscape. This vulnerability comprises from the slope, water resources, village wise forest density, NDVI and LULC etc. These factors are main role playing in suitability and vulnerability of tiger species.

According to tiger experts and self-observation, this vulnerability mainly depends on relief and slopes factor, because tiger is always using gentle slope and valley areas due to water availability as well as access to easily food and shelter, but occasionally they can move towards upper areas after a feed of food and drinking water. But most the time, they are using the lower areas. According to relief map, it is a component of physical vulnerability it has been considered that the areas with an elevation between 67 and 155 meters are the least vulnerable and most favoured by a tiger. Because of, this area have low altitude area have a high density of preys, water, shelter and migration rather than high altitude areas such as areas score low vulnerability. The regions with high altitude i.e. 332 to 450 meters are not suitable for tiger habitat and therefore such regions score high vulnerability. (Figure 2.)

Water is the most important component of the tiger species due to daily drinks and swimming in the summer season. In the corridor, water scarcity is the common phenomena due to impact of semi-arid zones. The Chambal River is only perennial river and flows from south-west to North East direction as well as Banas River which crosses in between Ranthambhore National Park and Kaila Devi Wildlife Sanctuary. The tiger corridor have major, broad, narrow and very narrow streams, which determines the strength and weakness of tiger corridor. Major streams are much stronger rather than very narrow streams due to water availability, which is the main pulling factor for big cats and other animals also. Major streams have low vulnerability and very narrow streams have a high vulnerability due to water scarcity in these particular areas. As well as tiger species always follow stream pathway because there is not human habitat and water availability so that major water stream is main attraction route and narrow stream is low attraction route of tiger species. Therefore major water streams have a low score of vulnerability and narrow water streams have high vulnerability of the corridor. (Figure 3.) 


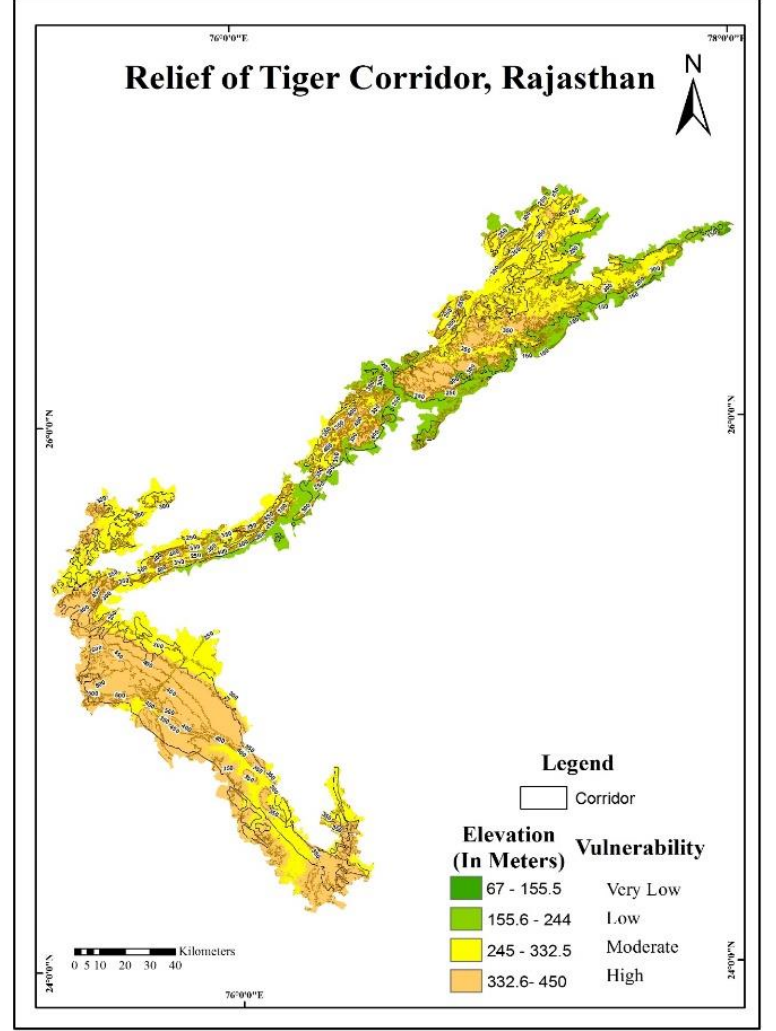

Figure 3. Relief Ranking

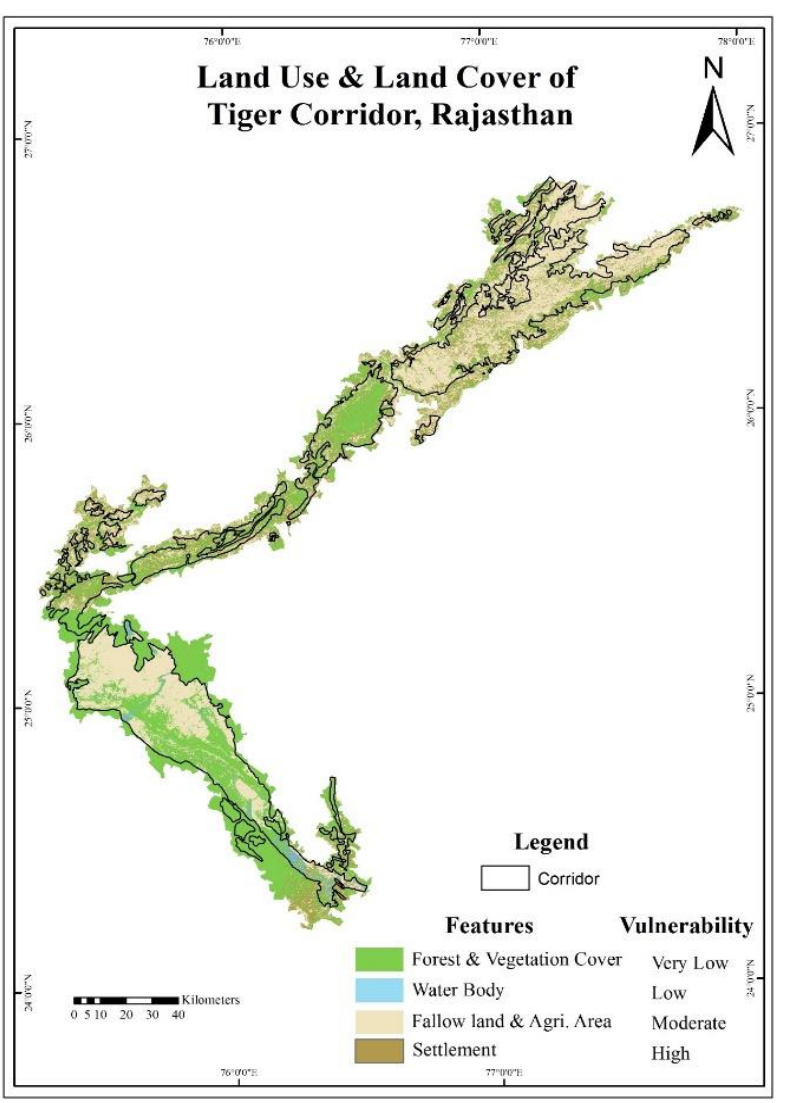

Figure 5. LULC Ranking

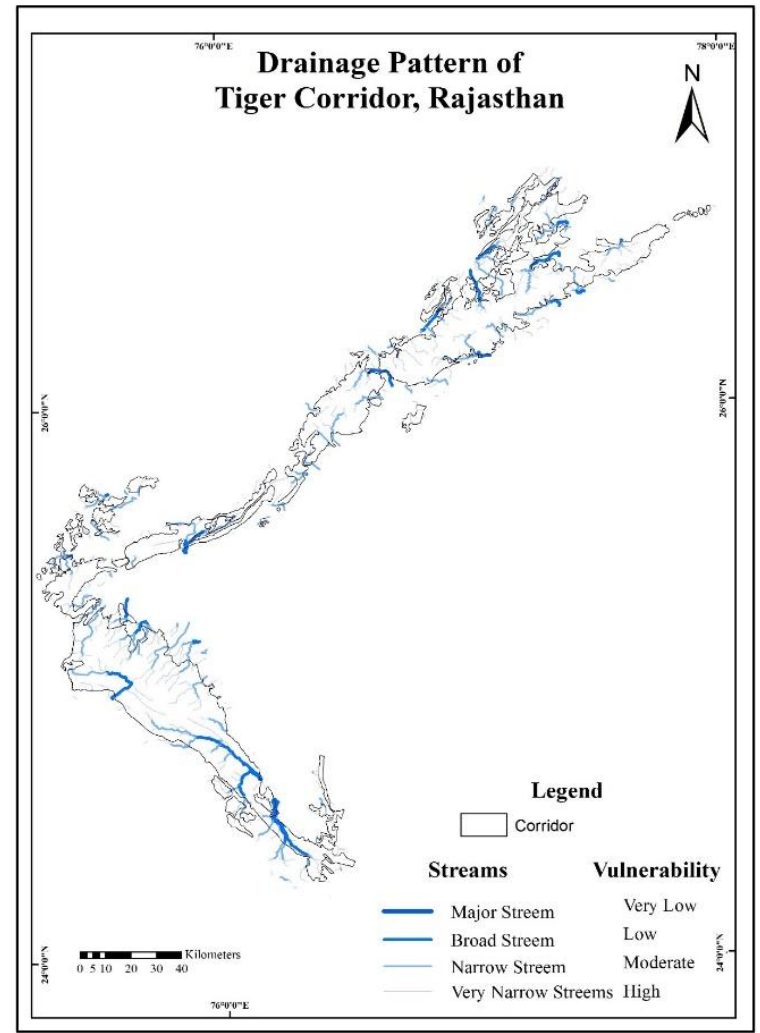

Figure 4. Stream Ranking

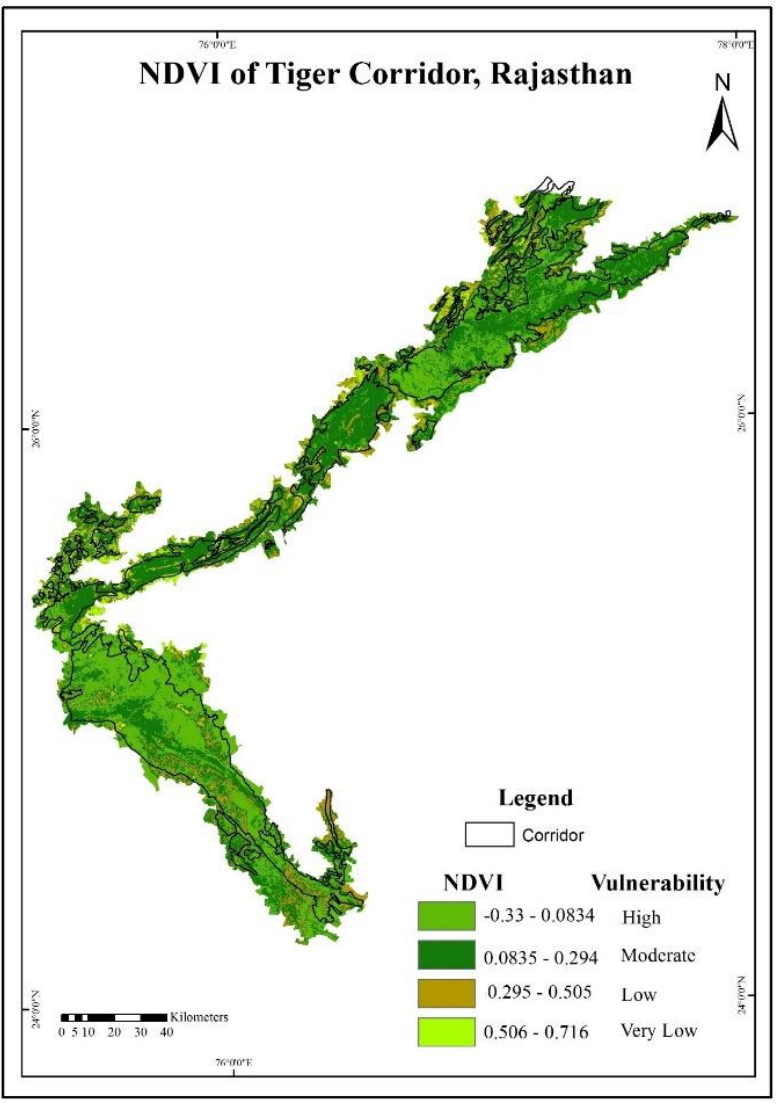

Figure 6. NDVI Ranking 


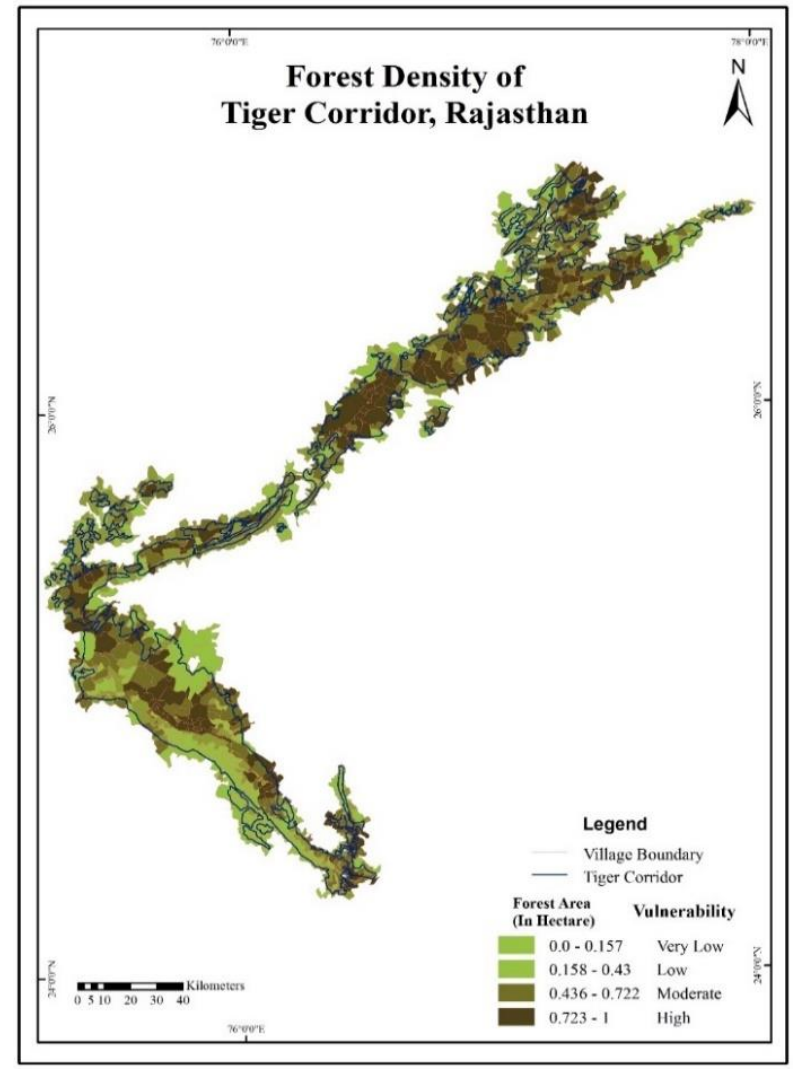

Figure 7. Forest Density Ranking

According to LULC map, the most favorable places for tiger habitat are high dense forest areas and vegetation cover because the availability of shelter and prey. There are a lot of reasons for degraded forest habitat due to deforestation, desertification, expansion bad land areas and urbanization. All 1499 villages, which are major concentration of tribal population and their livelihood based on primary activities. Therefore green cover regions have a low score of vulnerability and built up areas have high vulnerability of the corridor. (Figure 4.)

According to NDVI map, the high density of vegetation show a low score areas of vulnerability and low NDVI index areas show high score of vulnerability areas. Because the higher availability of shelter, drinking water, and easy prey in core areas rather than buffer areas. (Figure 5.)

According to village wise (1499), forest density, this species have the most favourable factor of tiger species. Low forest density have a high vulnerability scores due to human interference, lack of food and shelter and high density have low score, because suitable factors.

Eventually, physical vulnerability map, the core areas have a low vulnerability due to less human encroachment and high natural assets for the flourishing of tiger species. Meanwhile, the buffer areas have a high vulnerability due to human interference and scarcity of natural properties. Therefore, minimum impact in core areas due to specially, 'No-go zone areas", but buffer areas have a most physcial vulnerability of tiger habitat.

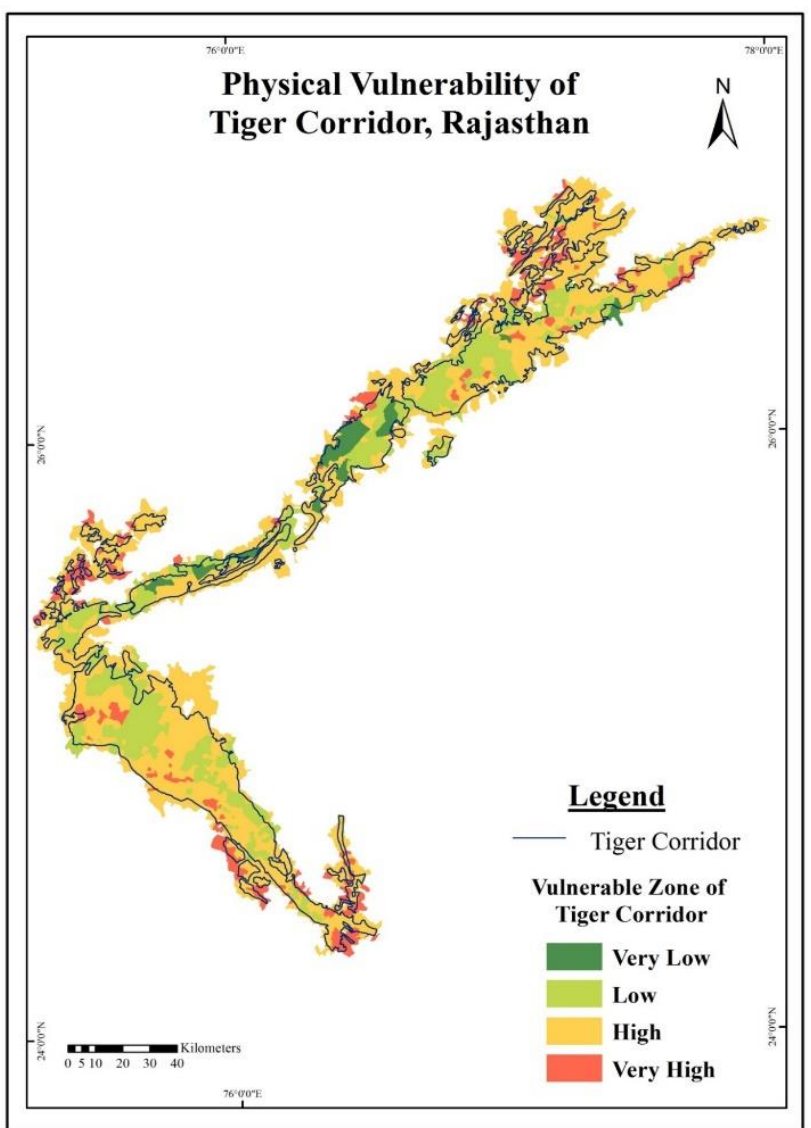

. Figure 8. Physical Vulnerability Ranking

In statistics analysis, a Q-Q plot is a quintilequintile plot which shows a probability plot of tiger corridor. It is comparing two probability distribution of observed and expected score of vulnerability. The observed score very close to normality line i.e. good 
relation in core areas and less correlated in buffer areas.

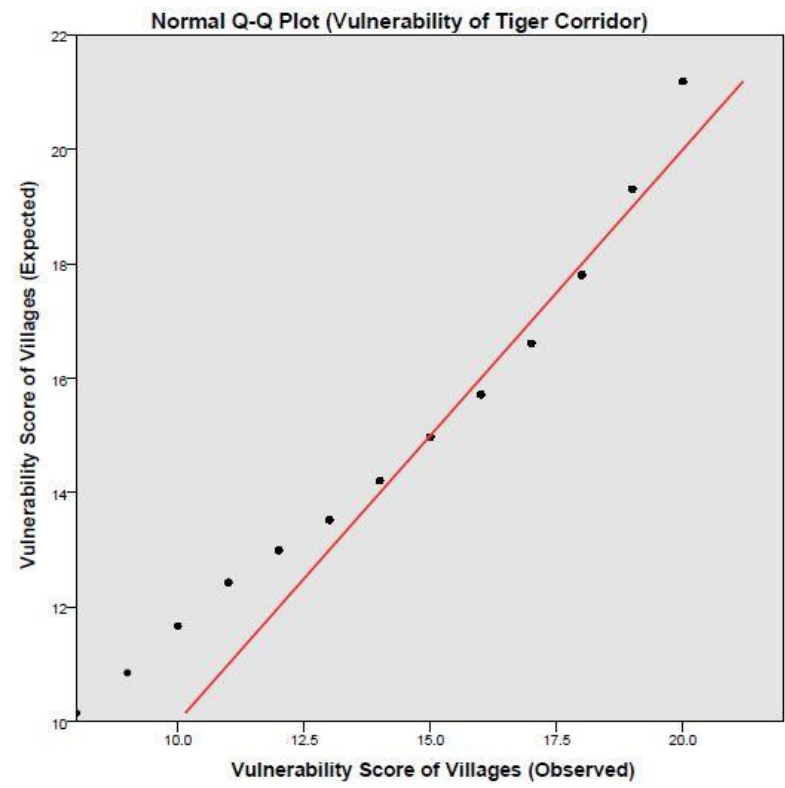

Figure 9. Physical Vulnerability Score of Tiger Corridor

\section{Conclusion}

The pattern of physical vulnerability of tiger habitat areas diverse in low lying grounds, valleys, water bodies, rivers, high dense forest areas, meanwhile these areas are not suitable for tiger habitats such as higher mountains, scarcity of water areas, less density of water streams, low vegetation cover and high settlement areas. There is very less availability of drinking water, shelter and preys. Core areas considered least vulnerable and most favourite place for a tiger. Meanwhile buffer areas are degrading through anthropogenic activities Therefore, tiger population is more flourishing in core areas rather than buffer areas due to less human intervention, the strength of physiography condition, water availability and no-go zone areas.

Buffer areas is suffering from less tiger population and human tiger conflicts because of continuously human encroachment is increasing by tribal population which belong from deprive section society and they have a very less livelihood option.
Finally, alarm condition for tiger species. Thus, viable population of tigers are providing sustainable ecological cycle without distorting the natural habitat and biological balance for man-environment relationship.

\section{References}

Beier. P.. \& Loe. S. (1992). In mv experience: a checklist for evaluating impacts to wildlife movement corridors. Wildlife Society Bulletin (1973-2006), 20(4), 434-440.

Beier, P.. \& Noss. R. F. (1998). Do habitat corridors provide connectivitv? Conservation biology, 12(6), 1241-1252.

Bennett, A.F. (2003). Linkages in the Landscape: The Role of Corridors and Connectivity in Wildlife Conservation. IUCN, Gland, Switzerland and Cambridge, UK. xiv + pp. 254.

Crooks, K. R. (2002). Relative sensitivities of mammalian carnivores to habitat fragmentation. Conservation Biology, 16: 488-502.

Davis, G. L. and R. W. Howe (1992). Juvenile dispersal, limited breeding sites, and the dynamics of metapopulations. Theoretical Population Biology, 41: 184-207.

Ferreras, P. (2001). Landscape structure and asymmetrical inter-patch connectivity in a metapopulation of the endangered Iberian lynx. Biological Conservation, 100: 125-136.

Forman, R. T. T.. \& Godron. M. (1986). Landscape Ecology Wiley New York, USA.

Gilpin, M. E. (1986). Minimum viable populations: processes of species extinction. Conservation biology: The science of scarcity and diversity, 19-34.

IUCN, (2003). Action Plan for the Management of Trans frontier Elephant Conservation Corridors in West Africa. (https://cmsdata.iucn.org/downloads/ apn_wcor0306_en.pdf Accessed on 2-7-2016.

Jhala, Y. V., Qureshi. Q., Gopal. R. and P.R. Sinha (Eds.). (2011). Status of tiger copredators, and prey in India, 2010. National Tiger Conservation Authority, Govt. of India, New Delhi, and Wildlife Institute of India, Dehradun. TR 2011/003 pp- 302.

Kothari, A. 1997. Conserving India's Agro-biodiversity: Prospects and Policy Implications. Gatekeeper Series no. 65, International Institute of Environment and Development, London

Mann, C. C., \& Plummer, M. L. (1995). Are wildlife corridors the right path? Science, 270(5241), $1428-1431$ 